\title{
On the Arteries of the Hand of Macacus Cyclopsis
}

\author{
by \\ Masahiko Mori \\ First Departmen of Anatomy \\ (Director: Prof. Dr. Junichiro Sato h) \\ Faculty of Medicine, Nagasaki University
}

\section{Foreword}

The vasuclar system of primates has been described by Göppert (1902-06), E. Müller (1904), Zuckerkandl (1907), Manners-Smith (1911), Nishi (1939), and others. However, many of these studies had been done on a comparatively small number of cases and statistical investigation of a large sample of the same species is few. This is felt to be particularly so in the case of vessels of the hand.

In the discussion of the normal state or anomalies of an organ in an animal it is necessary to reduce errors due to individual variations to the minimum. Therefore, there is a need to study not only animals of the same species but also a large number of material must be studied. For this reason, a detailed morphological investigation is being done in this department on the various organs and systems on the large number of Macacus cyclopsis which had been collected by Professor $\mathrm{Junichiro} \mathrm{Satoh}$ in order to ascertain the normal condition of Macacus cyclopsis. As a part of this study, I have investigated the arteries of the hand. The finding are reported.

\section{Material and Method}

The material consisted of a total of 100 hands from 59 male (right 30, left 29) and 41 female (right 20, left 21) formalin fixed Macacus cyclopsis bodies preserved in this department. Observations were done with utmost care under a magnifying glass using a small pointed knife used in ophthalmology, forceps and tweezers. In addinion to gross estimation of size, the arteries were measured as accurately as possible with a micrometer calibrated to $1 / 100 \mathrm{~mm}$. 


\section{Findings and Consideration}

A. Arteries of back of hand

The arteria radialis which descends along the flexor side of the forearm from the fossa cubitalis towards the processus styloideus of the radius curves around the distal side of the processus styloideus and passes on the palmar side of the tendon of insertion of the $M$. abductor pollicis longus to the back of the hand where it runs obliquely on the palmar side of the tendons of the M. extensor pollicis longus and the $M$. extensor carpi radialis longus. It then changes its course at between the tendons of the $M$. extensor carpi radialis longus and $M$. extensor carpi radialis brevis to run parallel to the long axis of the hand to the second intermetacarpal space where it becomes the A. metacarpea dorsalis II.

The A. radialis is the largest artery on the back of the hand and gives rise to one or two branches. One branch arises from the main trunk of the $A$. radialis at the radial side of the tendons of the M. extensor pollicis longus, and runs on the palmar side of the tendon of the $M$. extensor pollcis longus to the first intermetacarpal space where it becomes the A. metacarpea dorsalis I after sending a ramus perforans to the palm.

Another branch, the ramus carpeus dorsalis, separates from the main trunk at the radial side of the tendons of the $M$. extensor pollicis longus, and passes across under the tendons of the M. extensor pollicis longus, the $M$. extensor carpi radialis longus and the $M$. extensor carpi radialis brevis to the ulnar side.

Above and beneath the Retinaculum extensorum is the rete carpi dorsale, formed by the $\mathrm{A}$. interossea anterior, the ramus carpeus dorsalis a. radialis and the $A$. ulnaris. Also, on the line joining the bases of the Os metacarpale II-V is noted the so-called cattella dorsalis which connects the $A$. radialis with the ramus carpeus dorsalis a. ulnaris.

The various Aa. metacarpeae dorsales descend between the respective metacarpal bones and connect with the arcus palmaris profundus by the Rami perforans at the paoximar side (Fig. 1).

1. Course of $\mathrm{A}$. radialis on back of hand

Adachi (1928) has classified the course of the A. radialis on the back of the hand of the Japanese into 6 types according to the relation between the tendons and the intermetacarpal spaces. I have applied the classification of Adachi in this study, but the M. extensor 


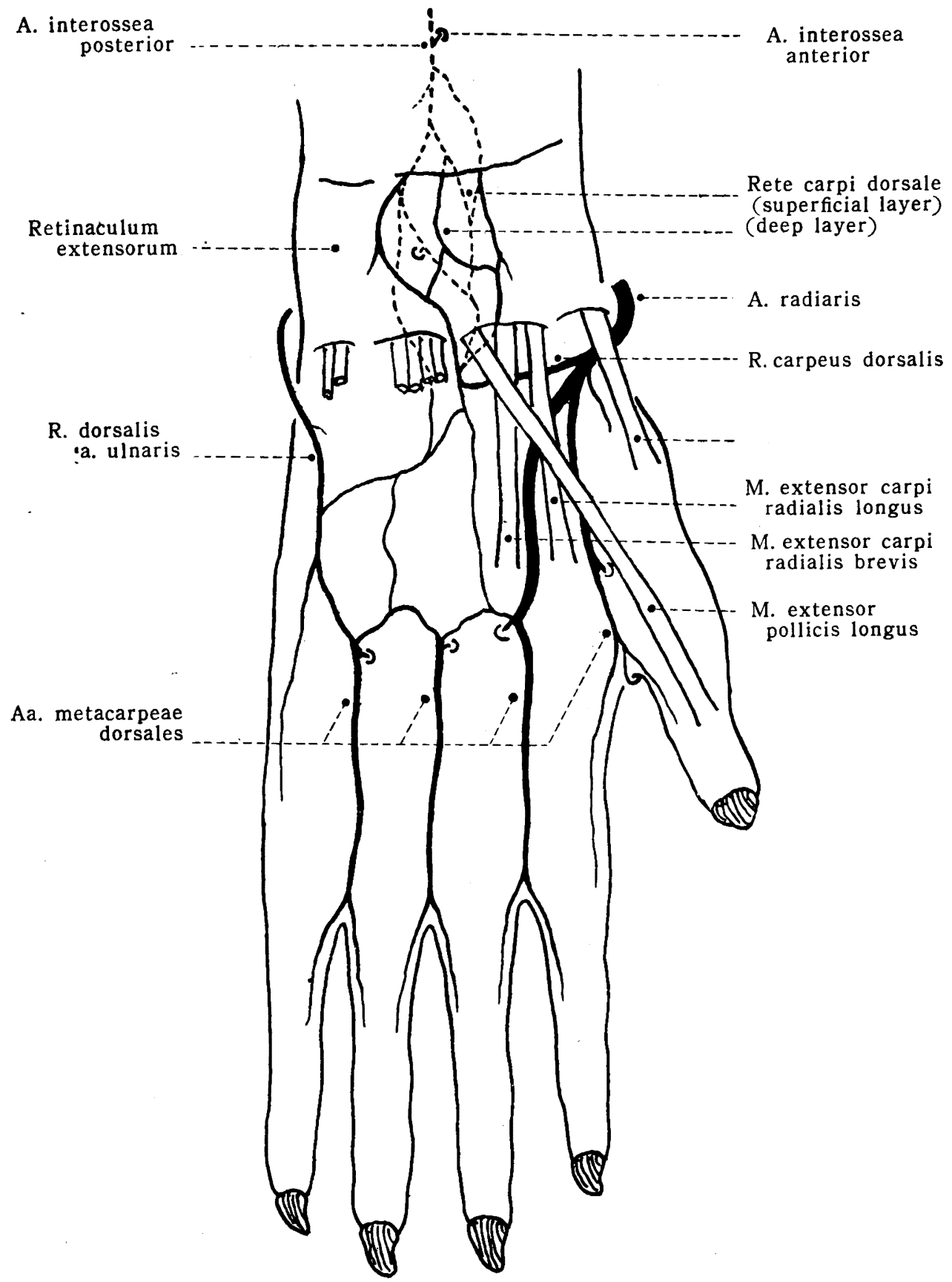

Fig. 1 Arteries of back of hand of Macacus cyclopsis 
pollicis brevis is not found in Macacus cyclopsis. (Fig. 2, Table. 1) In types $\mathrm{I}$ to $\mathrm{V}$, the $\mathrm{A}$. antebrachii dorsalis superficialis is absent

Table 1. Course of A. radialis on back of hand.

\begin{tabular}{|c|c|c|c|c|c|}
\hline Type I & Type II & Type III & Type IV & Type V & Type VI \\
\hline 1 & 40 & 3 & 0 & 56 & 0 \\
$(1.0 \pm 0.99)$ & $(40.0 \pm 4.89)$ & $(3.0 \pm 1.70)$ & & $(56.0 \pm 4.96)$ & \\
\hline
\end{tabular}

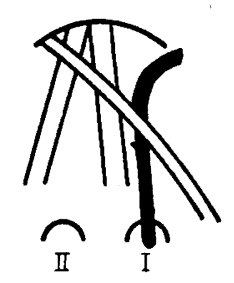

Type I

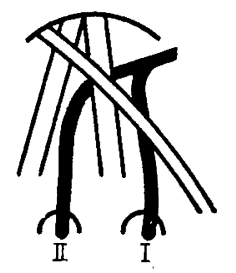

Type II

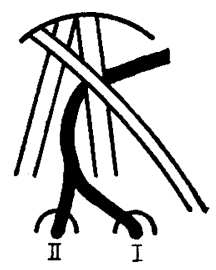

Type III

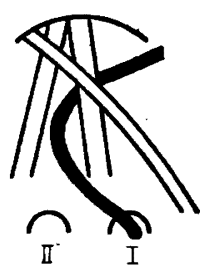

Type IV

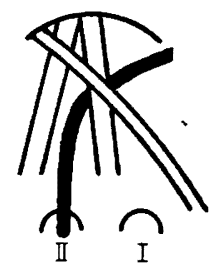

Type V

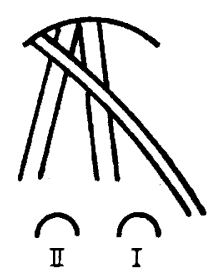

Type VI

Fig. 2 Course cf A. radialis on back of hand

Prof. Adachi's original schemes are a little changed by the author, because

M. extensor pollicis brevis is absent in Macacus cyclopsis.

and when the A. metacarpea dorsalis I and II are double, only the well developed one which arises from the A. radialis was considered. The other was ignored.

Type I :

The A. rdialis passes on the palmar side of the dorsal tendons of the M. abductor pollicis longus, the M. extensor pollicis longus and descends along the radial side of the tedon of the $M$. extensor carpi radialis longus to the first intermetacarpal space. The ramus carpeus dorsalis, which passes across the palmar side of the tendon of the M. extensor carpi radialis longus, is always smaller. This is the normal from in man.

In my study of Macacus cyclopsis, I case (body No. 3, female, right) $(1.0 \% \pm 0.99 \%)$ was this type. However, in this case there was separation into two arteries as in type II, but there was definite difference in the size of the two. As the larger artery extended to the first intermetacarpal space it was included as type $I$ but in the strict sense, it is not type I of Adachi.

Type II :

The A. radialis separates into two branches of equal size beneath 
the dorsal tendons of the thumb. The radial branch descends along the radial side of the tendon of the $M$. extensor carpi radialis longus to the first intermetacarpal space as in type I. The ulnar branch crosses over the palmar side of the tendon of the M. extensor carpi radialis longus to the ulnar side and further it descends between this tendon and the tendon of the M. extensor carpi radialis brevis to the second intermetacarpal space.

In Macacus cyclopsis, 40 cases (right 18 , left 22$)(40.0 \% \pm 4.89 \%)$ were of this type of which 22 were male and 18 female. Type III :

The A. radialis runs on the palmar side of the dorsal tendons of the thumb and the tendon of the M. extensor carpi radialis longus, and just after it descends between the latter and $M$. extensor carpi radialis brevis, it separates into two branches of equal size. One goes to the first intermetacarpal space while the other reaches the second intermetacarpal space. The A. radialis does not pass on the radial side of the tendon of the M. extensor carpi radialis longus or there is only a rudimentary twig.

In Macacus cyclopsis, 3 cases (male) $(3.0 \% \pm 1.70 \%)$ were of this type and the $\mathrm{A}$. radialis did not descend along the radial side of the M. extensor" carpi radialis longus.

Type IV :

The A. radialis passes over the palmar side of the dorsal tendons of the thumb and the tendon of the M. extensor carpi radialis longus to the ulnar side and runs on the ulnar side of the tendon of the $M$. extensor carpi radialis longus between the tendons of the $M$. extensor carpi radialis longus and brevis, then goes around the distal portion of the insertion of this tendon to the radial side and extends to the first intermetacarpal space. Further, the arterial trunk is not seen to pass along the radial side of the tendon of the M. extensor carpi radialis longus.

In Macacus cyclopsis not a single case belonged to this type. Type V:

The A. radialis passes palmar to the dorsal tendons of the thumb and the tendon of the $M$. extensor carpi radialis longus and descends between the tendons of $M$. extensor carpi radialis longus and brevis to the second intermetacarpal space. The A. radialis does not pass on the radial side of the tendon of the $M$. extensor carpi radialis longus.

In Macacus cyclopsis, 56 cases (right 30 , left 26$)(56.0 \% \pm 4.96 \%)$ 
were of this type. By sex there 34 males and 22 females. In the strict sense, however, only one case (body No. 79, male, right) was of this type. In 53 cases, an artery descending on the radial side of the tendon of the M. extensor carpi radialis longus to the first intermetacarpal space was present as in type II but being smaller than that on the ulnar side, it was disregarded. In the remaining one case (body No. 60, male, right) the course was the same as in type III but the artery to the first intermetacarpal space was much smaller than that to the second intermetacarpal space and the smaller one was disregarded. Also the following special case which demonstrated a peculiar course is included.

Special case (body No. 52, male, right)

The A. radialis, after giving rise to the ramus palmaris superficialis a. radialis on the forearm, follows the pathway of type $\mathrm{V}$ on the back of the hand to the second intermetacarpal space. In addition, a small branch is sent off from the A. radialis very high on the forearm (moro proximal than the origin of the ramus palmaris

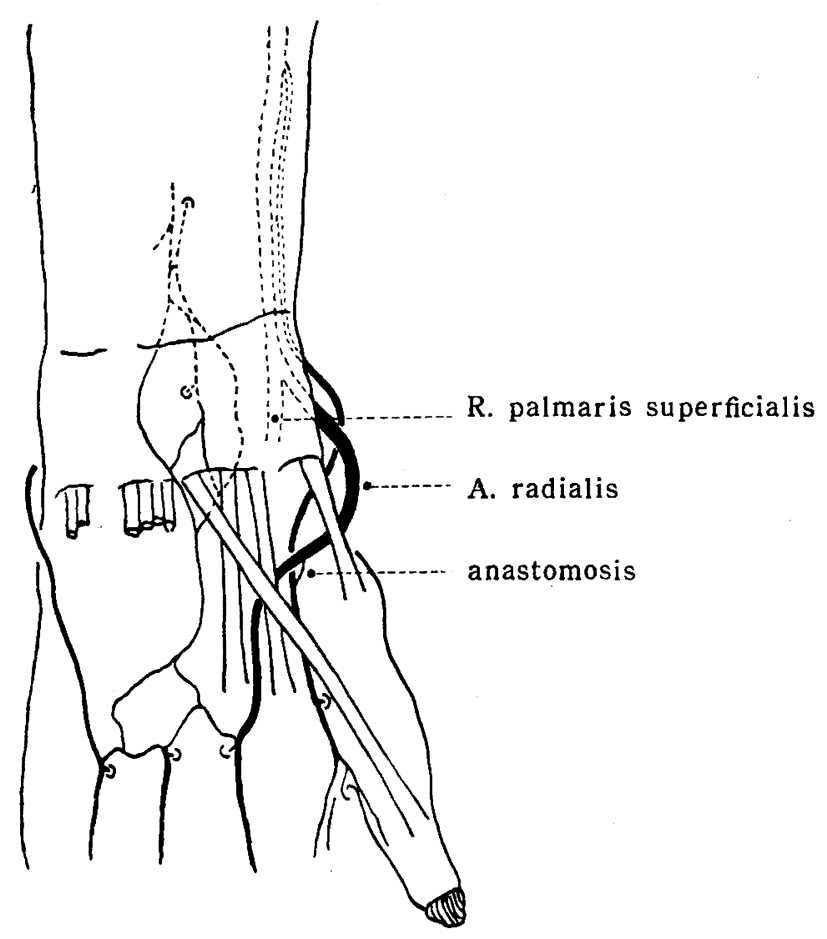

Fig. 3 Special case of distribution (body No. 52, $\hat{o}, \mathrm{r}$.) 
superficialis) which descends parallel to the main trunk and goes around the processus styloideus of the radius to appear on the back of the hand where it passes on the palmar side of the dorsal tendons of the thumb. After receiving a small branch from the former (the artery to the second intermetacarpal space), it descends along the radial side of the tendon of the $M$. extensor carpi radialis longus to the first intermetacarpal space as in type I. (Fig. 3)

Type VI:

In this type, the A. antebrachii dorsalis superficialis is present.

None of our Macacus cyclopsis were of this type.

In other words, in Macacus cyclopsis the majority of cases were types V and II. Furthermore, as described above, in most cases of type $\mathrm{V}$ the artery followed exactly the same course as in type II even though there is a differece in size of the branches. If importance is not placed on the size or predominance of the branches, types III, II and V may be regarded as being the same. Therefore, in Macacus cyclopsis the A. radialis most usually divides into two branches beneath the dorsal tendons of the thumb. One branch, the radial branch, descends along the radial side of the tendon of the $M$. extensor carpi radialis longus to the first intermetacarpal space while the other, the ulnar branch, passes over the palmar side of the tendon of the M. exensor carpi radialis longus to the ulnar side and then descends between this tendon and the tendon of the M. extensor carpi radialis brevis to the second intermetacarpal space. When the relation to the dorsal tendons and the presence or absence of $\mathrm{A}$. antebrachii dorsalis superficialis is ignored and only the entry into the second intermetacarpal space is taken into consideration, entry into the second intermetacarpal space is noted in 99 out of 100 cases $(99.0 \% \pm 0.99 \%)$ of Macacus cyclopsis.

Entry of the A. radialis into the second intermetacarpal space is very rare in $\operatorname{man}(6.2 \%$ in white people, $2.5 \%$ in Japanese adult, $4.5 \%$ in Japanese fetus, $8.8 \%$ in Northern Chinese adult). There is a difierence by race in the frequency being more frequent in the white race than Japanese ( $\mathrm{L} \circ \mathrm{th}$ ). However, this condition is the most usual form in Macacus cyclopsis.

On review of literature, $\mathrm{Parsons}$ says that the $\mathrm{A}$. radialis in mammals has two areas of penetrtion; One at the first intermetacarpal space and the other at the second intermetacarpal space (according to Adachi). For primates also, in such Prosimiae as Lemur macaco, Lemur catta, etc., the small branch penetrates at the first intermeta- 
carpal space but the main trunk extends to the second intermetacarpal space (Schwalbe, Manners-Smith). Furthermore, in Simiae there are. instances in which the main trunk reaches the first intermetacarpal space such as in lower Lagothrix (Bang), but generally in such Cebidas as Ateles paniscus, Ateles arachinoides (Zuckerkandl), Chrysothrix, Cebus capucinus (Manners-Smith), etc., a small branch to the first intermetacarpal space is sometimes seen, but the main trunk goes to the second intermetacarpal space. It is reported that in such Cercopithecidae as Macacus rhesus, Macacus fuscatus, Macaus sinicus, Cynopithecus nigrescens, Semnopithecus Catellus, Cercocebus fuliginosus, Cercopithecus callitrichus (Manners-Smith, Nishi) the main trunk reaches the second intermetacarpal space with a slightly smaller branch going to the first intermetacarpal space. This finding was obtained in my own study also.

However, in Hominidae there is a gradual shift in the main trunk. That is, in Simia satyrus, Hylobates (Zuckerkandl, Manners-Smith) the main trunk still extends to the second intermetacarpal space but in Pan chimpanse, Gorilla gorilla (Zuckerkandl, Glidden, Garis, Manners-Smith) the main trunk penetrates the first intermetacarpal space as in man.

In man type I, in which the artery descends beneath the dorsal tedon of the thumb to the first intermetacarpal space, is reported to be the usual form and according to the classification of Adachi there is no difference between adult and fetus or between Japanese and Northern Chinese (Adachi, Mori, Fukuyama). However, there is marked difference between man and Macacus cyclopsis. That is, type $I$ is more frequent in man than Macacus cyclopsis, but type II and $\mathrm{V}$ are more frequent in macacus than man.

In view of the above literature and my findings, it is assumed that the usual course of the $A$. radialis on the back of hand of Prosimiae and lower Simiae is to reach and penetrate the second intermetacarpal space, but there is a gradual shift in the course of the main trunk and from the level of Hylobates, Simia satyrus, etc., the main trunk of $\mathrm{A}$. radialis reaches the first intermetacarpal space in higher Simiae as in man.

2. Ramus carpeus dorsalis a. radialis, Aa. metacarpeae, Rete carpi dorsale

In man the ramus carpeus dorsalis a. radialis is divided into two branches. One, after reaching the second intermetacarpal space, cotinues with the A. metacarpea dorsalis II, while the other passes 
across the palmar side of the tendon of the $M$. extensor carpi radialis brevis to form the rete carpi dorsale. However, in Macacus cyclopsis, the former branch which desceds between the tendons of the $M$. extensor carpi radialis longus and brevis to the second intermetacarpal space, corresponds to the ulnar branch of the A. radialis as mentioned in "the course of $A$. radialis on the back of hand." Consequently, in Macacus cyclopsis, the artery which arises from the $A$. radialis and runs to the rete carpi dorsale, or that which runs to the second intermetacarpal space by a different course from that of the ulnar branch is the ramus carpeus dorsalis.

The ramus carpeus dorsalis, thus defined, was absent in 17 cases (male 10, female 7) $(17.0 \% \pm 3.75 \%)$ of my Macacus cyclopsis. In the remaining 83 cases, a very small branch was noted. Of these cases, the ramus carpeus dorsalis arose in 78 cases $(78.0 \% \pm 4.14 \%)$ from the A. radialis. Furthermore, union with just the rete carpi dorsale was noted in 81 cases $(81.0 \% \pm 3.92 \%)$ while only two cases $(2.0 \% \pm 1.40 \%)$ demonstrated a different course from that of the main trunk with a branch to the second intermetacarpal space also. It is evident that the greater majority contributed to the formation of the rete carpi dorsale.

The A. metacarpea dorsalis I in Macacus cyclopsis is different from that in man (Mori). It is a direct continuation of the radial branch of A. radialis and, near the base of the first and second metacarpal bones, it sends off a so-called ramus perforans, which penetrates between the two heads of the M. interosseus dorsalis I to the palm, after which it descends on top of the Mm. interossei dorsales and shortly divides into two branches. One branch descends along the ulnar side of the Os metacarpale I and becomes the $\mathrm{A}$. dorsalis pollicis ulnaris after sending a branch to the A. volaris pollicis. The other branch descends along the radial side of Os metacarpale II to become the A. dorsalis indicis radialis. Further, the previously mentioned ramus perforans becomes A. metacarpea palmaris I on the palm and anastomoses with the end of the A. digitalis palmaris communis $I$.

A. metacarpea dirsalis II is derived from the descending A. radialis. The other Aa. metacarpeae dorsalis arise, as in man, from the rete carpi dorsale, :the ramus carpeus dorsalis or from the arcus palmaris profundus by the ramus perforans. The former two instances were regarded as dorsal origin and the latter as palmar origin and the incidence of eath in A. metacrpea dorsalis III and IV was investigated 
(table 2).

Table 2. Origin of A. metacarpea dorsalis III and IV.

\begin{tabular}{|l|c|c|}
\hline & III & IV \\
\hline Dorsal origin > Palmar origin & $\begin{array}{c}12 \\
(12.0 \pm 3.24)\end{array}$ & $\begin{array}{c}6 \\
(6.0 \pm 2.37)\end{array}$ \\
\hline Dorsal origin < PaImar origin & $(71.0 \pm 4.53)$ & $(79.0 \pm 4.07)$ \\
\hline Dorsal origin = Palmar origin & $\begin{array}{c}17 \\
(17.0 \pm 3.75)\end{array}$ & $(15.0 \pm 3.57)$ \\
\hline
\end{tabular}

In man, palmar origin of the Aa. metacarpeae dorsales tends to increase from the radial to the ulnar side (Adachi, Mori, Fuku yama). Simiarly in Macacus cyclopis, for the A. metacarpea dorsalis III, (dorsal origin < palmar origin) was more freqent than (dorsal origin > palmar origin) with a difference of $59.0 \% \pm 4.91 \%$, while for the A. metacarpea dorsalis IV, (dorsal origin < palmar origin) was much more frequent than (dorsal origin $>$ palmar origin) with a difference of $73.0 \% \pm 4.43 \%$. It shows a tendency as in man. However, it is reported that in Europeans, the A. metacarpea dorsilis II. III and IV arise sually from the ramus carpeus dorsalis and rete carpi dorsale (Adachi).

The rete carpi dorsale is, as in man, more developed than the rete carpi volare. It is formed by the ramus carpeus dorsalis a. radialis and ulnaris, the $A$. interossea dorsalis and the ramus dorsalis of the A. interossea anterior and consists of two layers, deep and superficial. The superficial layer is on the dorsal side of the lig. carpi dorsale and the deep layer is on the palmar side of this ligament.

The catella dorsalis proximales is a so-called chain of small arteries on the dorsal side of the proximal end of the metacarpal bones and connects the various A. metacarpea dorsalis. This arterial chain was noted in all cases but an incomplete chain was found in 18 cases (male 11 , female 7$)(18.0 \% \pm 3.84 \%)$. This arterial chain corresponds to the arcus dorsalis manus of Lineback. (1933).

B. Arteries in the palm

The A. radialis, at bout the middle of the forearm gives rise to the ramus palmaris. superficialis a. radialis.

This ramus palmaris superficialis descends side by side with the main trunk of the A. radialis in the forearm to the Proc. styloideus of the radius where the main trunk curves around to the back of hand. At this point it separates from the main trunk towards the thenar 
region and penetrates the $M$. abductor pollicis brevis to the palm.

On the other hand, the course of the A. ulnaris in the forearm describes an arch connecting the cubital fossa and Proc. styloideus of the ulna. It passes on top of the Retinaculum flexorum and runs to the palm on the radial side of the Os pisiforme. It is covered by the $M$. palmaris brevis and after giving rise to the ramus palmari's profundus a. ulnaris in this area, joins with the previously mentioned ramus palmaris superficialis a. radialis to form the arcus palmaris superficialis beneath the aponeurosis palmaris.

Four A. digitalis palmaris communis arise from the convexity of the arcus palmaris superficialis which become the A. digitales palmaris propria of the ulnar side of the thumb, index finger and middle finger and the radial side of the ring and small fingers.

The ramus palmaris profundus a. ulnaris sinks deep between the M. abductor digiti minimi and the M. flexor digiti minimi brevis, passes over the palmar side of the $\mathrm{Mm}$. interossei on the dorsal side of the $\mathrm{Mm}$. contrachentes to the radial side where it anastomoses with the ramus perforans of the A. radialis which appears on the palm from the dorsal side after penetrating the second intermetacarpal space to form a fine arcus palmaris profundus. The various A. metacarpea palmaris arise from the convexity of this arch and these arteries anastomose with Aa. digitales palmaris communes (Fig. 4).

1. Ramus palmaris superficialis a. radialis

The course, anastomoses with other arteries, height of bifurcation and size of the ramus palmaris superficialis a. radialis were studied.

1) Course and anastomoses

As previously mentioned, the ramus palmaris superficialis arises from the $A$. radialis at about the middle of the forearm and descends side by side with the $A$. radialis to the distal end of the Proc. styloideus of the radius where the $A$. radialis curves to the back of hand. At this point, it separates from the A. radialis and goes to palm. In some cases, both arteries are joned by small $(1-3 \mathrm{~mm})$ anastomosing branches (18 cases-male 10, female 8, 18.0\% $\pm 3.84 \%$ ). One of these cases had a compratively long $(28.0 \mathrm{~mm}$ ) anastomosing branch (body No. 77, female, right) (Fig. 5).

The state of penetration through the M. abductor pollicis brevis by the ramus palmaris superficialis was reviewed. This artery penetrated the M. abductor pollicis brevis in 70 cases (male 39, female 31$)(70.0 \% \pm 4.58 \%)$, passed on the dorsal side of this muscles in 29 cases (male 19, female 10) $(29.0 \% \pm 4.53 \%)$ and passed on the 


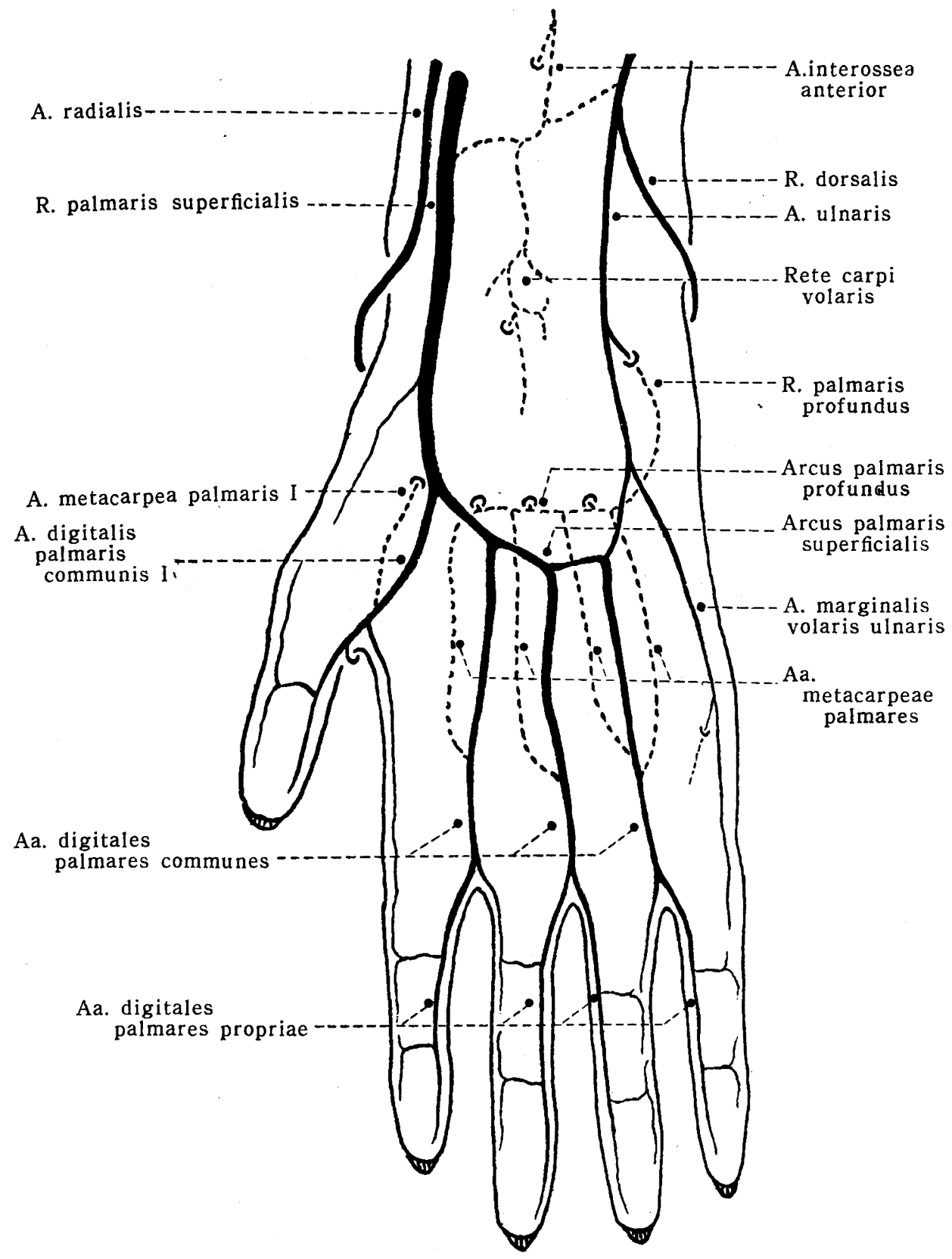

Fig. 4 Arteries of palm of Macacus cyclopsis 
palmar side in 1 case (male, left) $(1.0 \% \pm 0.99 \%)$.

In general, this artery in macacus descends on top of the thenal muscles (Nishi), while in Simia satyrus it passes deep beneath the thenal muscles ( $\mathrm{M}$ a nners-Smith). However, in man it either denetrates the thenal muscles or passes on the surface of the muscles. My findings on Macacus cyclopsis are similar to the condition in man.

2) Height of bifurcation

In the measurement of the height of bifurcation of the ramus palmaris superficialis, the distance between the distal edge of the bifurcation point and the point of entry into the osteofibrous canal of M. flexor carpi radialis (which corresponds to the proximal surface of tuberculum ossis scaphoidei) was measured. Further, the distance between the proximal end of the olecranon and the distal end of the Proc. styloideus of the ulna was regarded as the length of the forearm. Comparison was made with the former and the following results were obtained.

In the 100 cases examined, the average length of the forearm was $139.1 \mathrm{~mm}$ and the average height of bifurcation was $56.9 \mathrm{~mm}$. The relative distance to the bifurcation was 42.34 to a forearm length of 100. The bifurcation is close to the center of the forearm.

The height of bifurcation was less than 10 in only 6 cases $(6.0 \% \pm 2.37 \%)$ and in the remaining 94 cases $(94.0 \% \pm 2.37 \%)$ the bifurcation was much higher. In the greater majority of these 94 cases, the bifurcation was close to the middle of the forearm. The greatest hight was $115.3 \mathrm{~mm}$ (length of forearm $153.0 \mathrm{~mm}$ ) for a relative distance of 75.35 (body No. 16, female, right).

The ramus palmaris superficialis is said to appear from Prosimiae. It arises at about the center of the forearm in Lemur macaco (Schwal be) and at within $1 \mathrm{~cm}$ of the Retinaculum flexorum in Lagothrix (B a $\mathrm{g}$ ) but in Simiae, it arises at the lower forearm in lower Ateles hypoxanthus ( $\mathrm{M}$ a $\mathrm{n} \mathrm{n}$ e $\mathrm{r}-\mathrm{S} \mathrm{m}$ i $\mathrm{t} h$ ), at the carpal region in Ateles arachinoides ( $\mathrm{Zuckerkandl}$ ), at about one half inch from the wrist joint in Cebus (Manners-Smith) and in the region of sulcus radialis in Cebus capucinus ( $\mathrm{Zuckerkandl).}$ Further, in Macacus radiatus, it arises at slightly above the middle of the forearm, in the lower one third of the forearm in Macaus rhesus, near the middle in Cercocebus fuliginosus, slightly below the middle of the forearm in Cercopithecus callitrichus (M a n ners$\mathrm{S} \mathrm{mith)} \mathrm{and} \mathrm{slightly} \mathrm{distal} \mathrm{to} \mathrm{the} \mathrm{middle} \mathrm{of} \mathrm{the} \mathrm{forearm} \mathrm{in} \mathrm{Simia}$ inunus ( $\mathrm{T}$ he ile). My findings on Macacus cyclopsis are similar to 
these reports. However, a case has been reported in which the origin was found to be near the distal end of the radius in Macacus rhesus ( $\mathrm{Z} \mathrm{uckerkandl).} \mathrm{The} \mathrm{origin} \mathrm{is} \mathrm{near} \mathrm{the} \mathrm{wrist} \mathrm{joint} \mathrm{in}$ Gorilla gorilla, Simia satyrus, Pan chimpanse, Hylobates, Troglodytes niger ( $\mathrm{M}$ a n ners-S mith, Z u kerkandl, Glide n, Garis).

On the other hand, the bifurcation is usually lateral to the wrist joint in man. It is said that there is no difference in this relation between races or between adult and fetus (A d a chi, Mori, $\mathrm{Fu} \mathrm{k} \mathrm{u} \mathrm{y} \mathrm{a} \mathrm{ma}$, e t c.).

From the above findings, it appears that the ramus palmaris superficialis a. radialis usually arises close to the middle of the forearm in Lemuroidae, Cebidae, Cercopithecidae, etc. and that in higher Pongidae, the bifurcation is near the wrist joint as in man.

3) Size

The size of the ramus palmaris superficialis was compared with the size of the A. radialis just below the bifurcation. The following results were obtained.

The average size of the ramus palmaris superficialis was $0.81 \mathrm{~mm}$ and the average size of the $\mathrm{A}$. radialis just below the bifurcation was $0.61 \mathrm{~mm}$ which shows that the former is larger. The ramus palmaris superficialis was larger than the A. radialis in 60 cases $(60.0 \% \pm 4.89 \%)$, the two were of equal size in 39 cases $(39.0 \% \pm 4.87 \%)$, while the ramus palmaris superficialis was smaller than $A$. radialis in 1 case $(1.0 \% \pm 0.99 \%)$. That is, the ramus palmaris superficialis was larger or equal to $\mathrm{A}$. radialis in 99 cases $(99.0 \% \pm 0.99 \%)$.

From the standpoint of comparative anatomy, the ramus palmaris superficialis is extremely small in Nycticebus, Chrysothrix, Cebus (Manners-Smith), Cebus capucinus (Z u ckekandl), but in Macacus rhesus ( $\mathrm{Z}$ ckerkandl, Manners-S mith), Macacus radiatus, Cynocephalus maimon and babuin, Cynopithecus (M a n n e r s -Smith), the ramus palmaris superficialis is larger than the A. radialis as in my own study of Macacus cyclopsis. The findings for Simia satyrus are inconsistent, some reporting the ramus palmaris superficialis to be larger ( $\mathrm{Zuckerkandl}$, Sonntag) while others

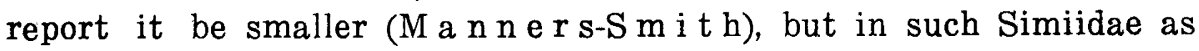
Troglodytes niger, Pan chimpanse, Simia inunus ( $\mathrm{u} \mathrm{ckerkandl,}$ Manners-Smith, Theile), the ramus palmaris superficialis is reported to be small.

In man A. radialis is larger than the ramus palmaris superficialis and; in exceptional cases with bifurcation high up on the forearm. 
the ramus palmaris superficialis tends to be better developed than in those of usual bifurcation (A d a chi, Mori, Fuk y a ma).

In other words, up to Cercopithecidae, the ramus palmaris superficialis is large but in higher Pongidae, its condition is similar to that in man.

Next, comparison of the size of the ramus palmaris superficialis and the A. ulnaris at the lower forearm revealed the following results.

Measurement of each artery at the point of entry into the Retinaculum flexorum showed the average size of the ramus volaris superficialis to be $0.81 \mathrm{~mm}$ and that of the A. ulnaris to be $0.44 \mathrm{~mm}$, the former being far larger. The ramus palmaris superficialis was larger than the A. ulnaris in 91 cases $(91.0 \% \pm 2.86 \%)$, the two arterier were of equal size in 9 cases $(9.0 \% \pm 2.86)$, while the ramus palmaris superficialis was smaller than the $A$. ulnaris in none of the case.

Consequently, of these three arteries, the ramus palmaris superficialis, A. radialis and A. ulnaris in Macacus cyclopsis, the ramus palmaris surerficialis is the largest.

2. Arcus palmaris superficialis

Heretofore, many workers have classified the distribution of superficial arteries in the palm according to the formation of archs, but from the stand point of comparative anatomy, this arch formation is said to be of little value ( $\mathrm{Schwalbe}$ ). A d a chi (1928) also considered the above arch formation to be a secondary phenomenon and insignificant. Because he considered the state of development of the A. ulnaris, the ramus palmaris superficialis a. radialis and the $A$. mediana in the palm to be highly significant, the arteries in the palm of Japanese adults were classified into the ulnar type, radio-ulnar type and medinar-ulnar type. Fukuy a ma (1938) has added a radiomediano-ulnar type, for a total of four types.

$I$ have attempted a classification according to the types of $\mathrm{Ad} \mathrm{a} \mathrm{c} \mathrm{hi} \mathrm{and} \mathrm{Fuk} \mathrm{u} \mathrm{a} \mathrm{ma.}$

1) Ulnar type

The Arcus palmaris superficialis is form by only the the A. ulnaris.

In this case, the ramus palmaris superficialis. a. radialis is entirely unrelated and, in most instances, terminates in the thenal muscles, but occasionally a very fine branch joins with the $A$. ulnaris or the volar artery of the thumb.

There was not a single case of this type in Macacus cyclopsis. 
2) Radio-ulnar type

The arcus palmaris superficialis is formed by the A. ulnaris and the ramus palmaris superficialis a. radialis. All cases of Macacus cyclopsis were of this type.

3) Mediano-ulnar type

The arcus palmaris superficialis is formed by the A. mediana and the A. ulnaris.

None of my cases were of this type.

4) Radio-mediano-ulnar type

The arcus palmaris superficialis is formed by three arteries, the A. radialis, the A. ulnaris and the A. mediana.

None of my cases were of this type.

The ramus palmaris superficialis a. radialis and A. ulnaris, which form this arch, were of equal size or the A. ulnaris was comparatively

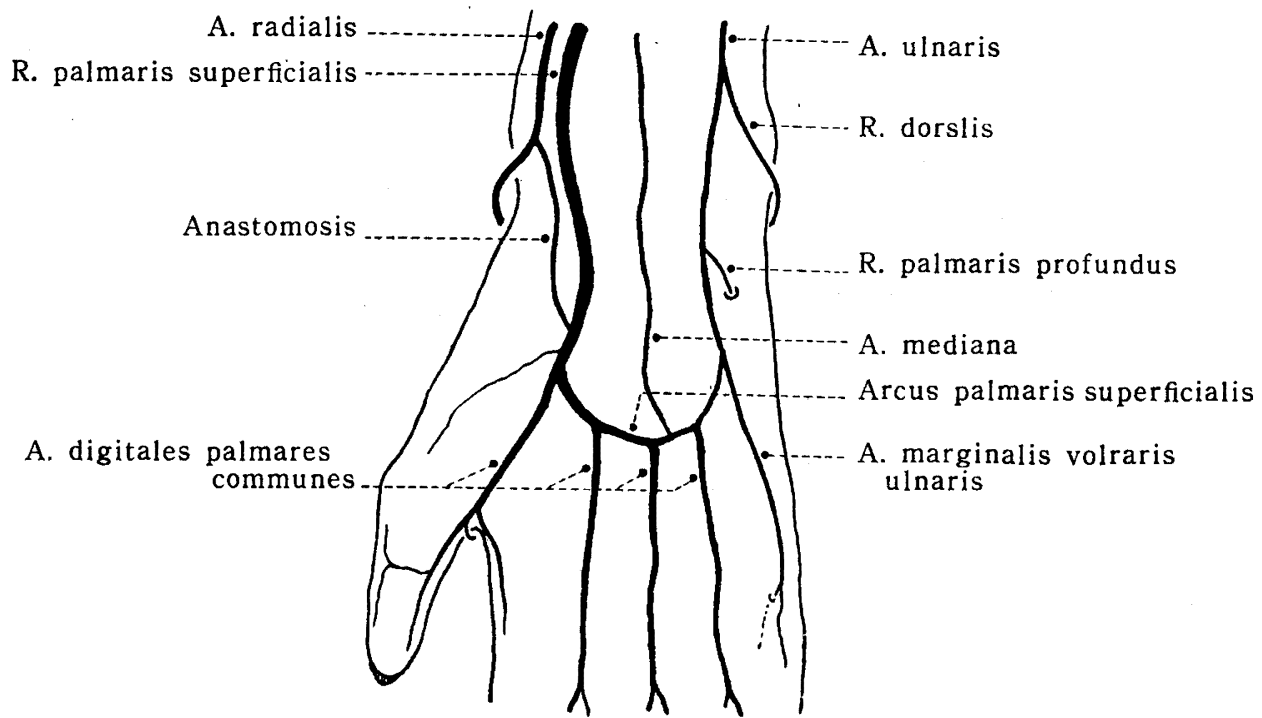

Fig. 5 Special case of distribution (body No. $77, \odot$, r.)

large in only a few cases (16 cases, $16.0 \% \pm 3.66 \%)$. The greater majority of cases hand a small A. ulnaris (84 cases, $84.0 \% \pm 3.66 \%$ ). Further, of these 84 cases, there was one case in which the development of the A. ulnaris was so poor that the arch appeared to be formed by only the ramus palmaris superficialis a. radialis (body No. 130, female, right). Also, there was a case in which an extremely small A. mediana was seen joining the arch (body No. 77, female, right) (Fig. 5). 
Next, the state of union between the A. ulnaris and the ramus palmaris superficialis was studied. Both arteries formed a complete arch in 92 cases $(92.0 \% \pm 2.71 \%)$ while both arteries were joined by a small liner anastomosing branch in 2 cases $(2.0 \% \pm 1.40 \%)$. In other words, union between these two arteries was seen in 94 cases $(94.0 \% \pm 2.37)$. No union was noted in the remaining 6 cases $(6.0 \% \pm 2.37 \%)$. Therefore, in the strict sense, these 6 cases do not have an arcus palmaris superficialis.

From the standpoint of comparative anatomy, Lemur macaco ( $\mathrm{S} \mathrm{chwalbe}$ ) are of mediano-ulnar type with the A. ulnaris being the main trunk. In Lemur catta, Stenopo tradigrada ( $\mathrm{Schwalbe}$ ), Nycticebus (M a ners-Smith), the A. mediana is primitive and small forming no arcus palmaris superficialis and the A. ulnaris constitutes the main trunk. In other words, such Prosimiae, as Lemuridae, Lorisidae, etc, are said to generally resemble the medianoulnar type. In Hapalidae ( $\mathrm{M} \mathrm{a} \mathrm{n} \mathrm{ne} \mathrm{r} \mathrm{s-S} \mathrm{m} \mathrm{ith)} \mathrm{and} \mathrm{in} \mathrm{such} \mathrm{Cebidae}$ as Ateles hypoxanthus, Lagothrix (M a n e r s-Smith), Ateles pan-

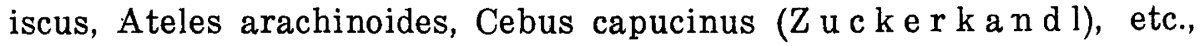
development of the ramus palmaris superficialis a. radialis is poor and they are of the ulnar type. However, there are some instances in which the ramus palmaris superficialis a. radialis is larger than the A. ulnaris and correspond to the radio-ulnar type such as in Chrysothrix (M a n n e r s-S m i t h). In such Cercopithecidae as Macacus rhesus ( $\mathrm{Manners-Smith,} \mathrm{Zuckerkadl)} \mathrm{Macacus} \mathrm{radiatus,} \mathrm{Ce-}$ rocebus fuliginosus, Cercopithecus callitrichus, Cynocephalus maimon, Cynocephalus anubis, Cynopithecus ( $\mathrm{Manners-Smith}$ ), etc., the ramus palmaris superficialis a. radialis is well developed and forms the main trunk of the arch and belong to the radio-ulnar type. However, Ma n ners-S mith (1911) reported that in Cercopithecus callitrichus, the ramus palmaris superficialis a. radialis and the $\mathrm{A}$. ulnaris are of equal size while in Cynocephalus babuin, the A. ulnaris forms the main trunk of the arch. $\mathrm{N}$ is hi (1939) has found the arcus palmaris superficialis in all of his macacus and usually the arch is formed by a well developed ramus palmaris superficialis a. radialis and a small A. ulnaris. Furthermore, in 15 cases $(83.33 \% \pm$ $8.74 \%$ ), the ramus palmaris superficialis was larger than the A. ulnaris, while in the remaining 3 cases $(16.67 \% \pm 8.74 \%)$ the two were of equal size. This finding generally is consistent with my own results.

In Hylobates (M a n ne r s-S m i t h), Troglodytes niger ( $\mathrm{Z} \mathrm{u} \mathrm{c} \mathrm{k} \mathrm{e} \mathrm{r-}$ $\mathrm{kand}$ ) and Gorilla gorilla (Ma nners-Smith, Z u ckerkandl, 
S o n n t a g), a definite arcus palmaris superficialis is not formed, but in such Pongidae as Simia satyrus, Pan chimpanse (M a n ners$\mathrm{Smith}, \mathrm{Zuckerk}$ and l, G lidde n, Garis, Son $\mathrm{tag}$ ), they are the ulnar type similar to man.

In man ulnar type is most frequent $(60.5 \%)$, followed by radioulnar type $(31.5 \%)$ and mediano-ulnar type is few $(8.0 \%)$ (A d a c h i). The frequency of the radio-mediano-ulnar type is slightly higher in fetus and child as compared with adult (Mori, Jaschtschinki). By race, the incidence of radio-mediano-ulnar type in northern Chinse adults is comparatively greater than in other races. With regard to the ulnar type, it has been reported that there are differences by race in that cases with all digital arteries arising from only the arcus palmaris superficialis formed by a well developed A. ulnarss with none from the arcus palmaris profundus are most frequent in Europeans followed by Chinese and is the least in Japanese. ( $\mathrm{Fu}$ k u y a ma)

3. Aa. digitales palmaris

In Macacus cyclopsis, the A. digitalis palmaris communis I-IV and the A. marginalis volaris ulnaris may be identified. Furthermore, as previously mentioned, the arcus palmaris superficialis in Macacus cyclopsis is only the radio-ulnar type. However, when a complete arch is formed by the A. radialis and the A. ulnaris, it was impossible to determine whether Aa. digitales palmaris arose from the former or the latter in some cases. In such cases, when the origin of the Aa. digitales palmaris is regarded simply as from the arcus palmaris superficialis, this means that the Aa. digitales palmaris is offset from either the ramus palmaris superucialis, a. radialis, the A. ulnaris, arcus palmaris superficialis, Aa. metacarpeae dalmaris (arcus palmaris profundus) or Aa. metacrpeae dorsales.

1) A. digitalis palmaris communis $I$

In Macacus cyclopsis, cases whith independent A. volaris pollicis radialis, A. volaris pollicis ulnaris and A. radialis indicis are very few and in the great majority of cases, these arteries arise by a single arterial trunk. Therefore, these arteries, including also the above mentioned independent forms, were regarded as the A. digitalis palmaris communis I.

The origin is from the ramus palmaris superficialis a. radialis in 84 cases (male 47 , female 37$)(84.0 \% \pm 3.66 \%)$, from the arcus palmaris superficialis in 15 cases (male 11 , female 4$)(15.0 \% \pm 3.57 \%)$ and from the arcus palmaris profundus in 1 case (male) $(1.0 \% \pm 0.99)$. 
Furthermore, independent A. volaris pollicis radialis was noted in 3 cases (male 1, female 2) $(3.0 \% \pm 1.70 \%)$, A. volaris ulnaris in 1 case (male) $(1.0 \% \pm 0.99 \%)$ and the radialis indicis in 1 case (male) $(1.0 \% \pm$ $0.99 \%)$.

As the A. digitalis palmaris communis I runs distal, it divides into the $\mathrm{A}$. volaris pollicis ulnaris and the A. radialis indicis in 40 cases (male 21 , female 19$)(40.0 \% \pm 4.89 \%)$, gave off the A. volaris pollicis radialis in addition to the above two arteries in 4 cases (male 2, female 2) $(4.0 \% \pm 1.95 \%$ ) and in 2 cases (male 1, female 1) $(2.0 \% \pm 1.40 \%)$ it separated into two arteries on the radial and ulnar sides of the thumb respectively.

2) A. digitalis palmaris communis II

This artery was noted in 91 cases (male 53, female 38$)(91.0 \% \pm$ $2.86 \%$ ). Of these, the origin was from the ramus palmaris superficialis a. radialis in 76 cases $(76.0 \% \pm 4.27 \%)$ and from the arcus palmaris superficialis in 15 cases $(15.0 \% \pm 3.57 \%)$.

Of the 9 cases (male 6 , female 3$)(9.0 \% \pm 2.86 \%)$ in which this artery was absent, a branch from the A. digitalis palmaris communis I crossed over beneath the tendon of the flexor muscle of the index finger and became the $\mathrm{A}$. digitalis palmaris of the index and middle fingers in 8 cases. In the remaining one case, the A. metacarpea dorsalis II penetrated the $\mathrm{Mm}$. interossei to the palm where it was joined by a small branch from the A. digitalis palmaris communis I, which came from beneath the tendon of flexor muscle of the index finger, and after which it becomes the A. digitalis palmaris of the index and middle fingers.

3) A. digitalis palmaris communis III

The artery is never absent. The origin is from the ramus palmaris superificialis in 85 cases (male 48 , female 37$)(85.0 \% \pm 3.75 \%)$. and from the arcus palmaris superficialis in 15 cases (male 11, female) $(15.0 \% \pm 3.75 \%)$.

4) A. digitalis palmaris communis IV

This artery is found in all cases. The origin is from the A. ulnaris in the majority of cases, 51 cases (male 26, female 25) $(51.0 \% \pm 4.99 \%)$, from the ramus palmaris superficialis a. radialis in 34 cases (male 22 , female 12$)(34.0 \% \pm 4.37 \%)$, and from the arcus palmaris superficialis in 15 cases (male 11 , female 4$)(15.0 \% \pm 3.57 \%)$.

5) A. marginalis volaris ulnaris

In Macacus cyclopsis, the A. mariginalis volaris ulnaris is a small branch from the A. ulnaris which descends along the ulnar 
edge of the hypothenar and sinks deep into the palm. The artery is found in 87 cases $(87.0 \pm 3.36)$.

This artery, in addition to sinking deep into the palm, given to a branch which descends further along the ulnar edge of the palm to become the A. volaris digiti quinti ulnaris in some of the cases. Such a branch or an artery from other areas which run along the ulnar edge on the palmar side of the small finger was considered to be the so-called A. volaris digiti quinti ulnaris and this artery was seen in 49 cases.

Review of the origin revealed that it arose from the A. ulnaris in 36 cases $(36.0 \% \pm 4.80 \%)$, from the arcus palmaris superficialis in

Table 3. Origin of Aa. digitales palmares communes.

\begin{tabular}{|c|c|c|c|c|c|}
\hline \multicolumn{2}{|c|}{ Artery } & $\begin{array}{l}\text { Superficial } \\
\text { arteries }\end{array}$ & $\begin{array}{l}\text { Aa. metac. } \\
\text { palm. (Arcus } \\
\text { palm. prof.) }\end{array}$ & \begin{tabular}{|} 
Aa. metac. \\
dors.
\end{tabular} & $\begin{array}{c}\text { Superficial } \\
\text { arteries and } \\
\text { Aa. metac. } \\
\text { palm. and dors }\end{array}$ \\
\hline \multirow{2}{*}{$\begin{array}{l}\text { Radial } \\
\text { side }\end{array}$} & A. digit. palm. comm. I & $\begin{array}{c}99 \\
(99.0 \%)\end{array}$ & $(1.0 \%)$ & 0 & ד \\
\hline & II & $(91.0 \%)$ & 0 & 0 & 0 \\
\hline \multirow{3}{*}{$\begin{array}{l}\text { Ulnal } \\
\text { side }\end{array}$} & III & $\begin{array}{c}100 \\
(100,0 \%)\end{array}$ & 0 & 0 & 0 \\
\hline & IV & $\begin{array}{c}100 \\
(100.0 \%)\end{array}$ & 0 & 0 & 0 \\
\hline & A. marg. vol. uln. & $\begin{array}{c}87 \\
(87.0 \%) \\
\end{array}$ & 0 & 0 & 0 \\
\hline
\end{tabular}

7 cases $(7.0 \% \pm 2.55 \%)$, from the A. metacarpea palmaris $\mathrm{V}$ in 3 cases $(3.0 \% \pm 1.7 \%)$, from the A. digitalis palmaris communis IV in 2 cases $(2.0 \% \pm 1.40 \%)$, and from the $\mathrm{A}$. metacarpea doralis IV in 1 case $(1.0 \% \pm 0.99)$. Next, the ramus palmaris superficialis a. radialis, the A. ulnaris and A. mediana whre considered to be superficial arteries of the palm while the Aa. metacarpeae palmares were regarded as deep arteries. The state of origin from these superficial and deep arteries and from the Aa. metacarpeae dorsales was studies by

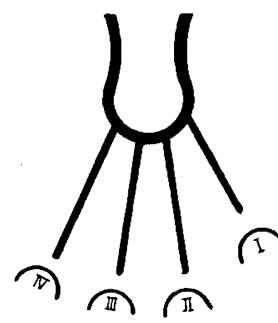

Type I

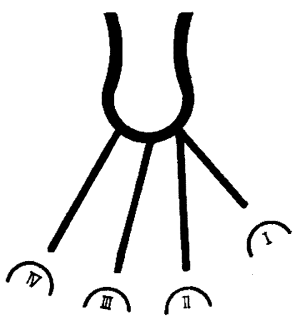

Type II

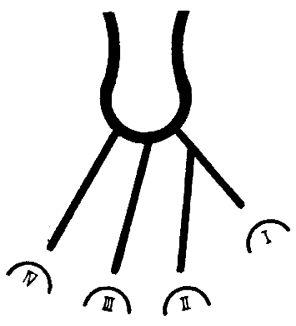

Type III

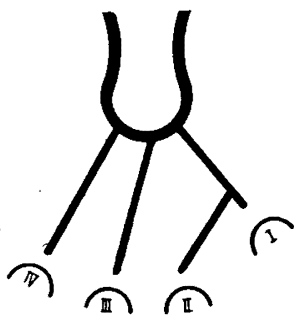

Type IV

Fig.,6 Types in the origin of A. digit. palm. comm. I and II 
dividing the hand into the radial and ulnar side at the long axis of the middle finger. It was found that in Macacus cyclopsis, superficial origin was more frequent on both sides (Table 3).

In addition, the state of origin of the $\mathrm{A}$. digitalis palmaris communis I and II from the superficial arteries of the palm may be classified into the following 4 types (Fig. 6.)

Type I :

The A. digitalis palmaris communis I and II arise from different parts of the superficial artery of the palm. The greatest number of cases, 44 cases (male 28 , female 16$)(44.0 \% \pm 4.96 \%)$ were of this type. Type II :

The A. digitalis palmaris communis I and II arise from the same place of the superficial palmar artery. 18 cases (male II, female 9) $(18.0 \% \pm 3.84 \%)$ were of this type.

Type III :

The A. digitalis palmaris communis I and II arise from the superficial artery of the palm by a single common arterial trunk which immediately divides into two branches. 28 cases (male 13, female 5) $(28.0 \% \pm 4.48 \%)$ were of this type. (The cases in which the A. digitalis palmaris communis I arose from arcue volaris profundus was excluded).

Type IV :

The A. digitalis palmaris communis II is absent in this type and a branch from the A. digitalis palmaris communis I runs to between the second finger. 9 cases $(9.0 \% \pm 2.80 \%)$ were found.

Comparison of the above findings whith those of $\mathrm{N}$ is hi (1939) for Macacus rhesus did uot reveal a marked difference between the two (Table 4).

Table 4. Types in the origin of A. digit. palm. comm. I and II.

\begin{tabular}{|l|c|c|}
\hline Reporter & Mori & Nishi \\
\hline Material & Macacus cyclopsis & Macacus rhesus \\
\hline No. of cases & 100 & 18 \\
\hline Type I & $44(44.0 \pm 4.96)$ & $8(44.4)$ \\
\hline Type II & $18(18.0 \pm 3.84)$ & $2(11.1)$ \\
\hline Type III & $28(28.0 \pm 4.48)$ & $6(33.4)$ \\
\hline Type IV & $9(9.0 \pm 2.86)$ & $2(11.1)$ \\
\hline
\end{tabular}


These findings were reviewed from the standpoint of comparative anatomy. In such Prosimiae as Lemur macaco ( $\mathrm{S} \mathrm{ch} \mathrm{w} \mathrm{a} l \mathrm{~b}$ e), Lemur catta, Nycticebus ( $\mathrm{M}$ a $\mathrm{n} n$ e r s-S m i t h), Chiromys madagascarensis

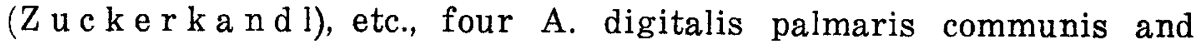
A. volaris ( $\mathrm{Z} \mathrm{u} \mathrm{c} \mathrm{k} \mathrm{e} \mathrm{r} \mathrm{k} \mathrm{a} \mathrm{n} \mathrm{d} \mathrm{l),} \mathrm{etc.,} \mathrm{four} \mathrm{A.} \mathrm{digitalis} \mathrm{palmaris} \mathrm{communis}$ and $A$. volaris digiti quinti ulnaris arise from the A. ulnaris or arcus palmaris superucialis having the A. ularis as the main trunk. In Hapalidae (Manners-Smith) also four A. digitalis palmaris communis arise from the A. ulnaris. Ateles (M a n n r s-Smith) have no thumb and are reported to have three A. digitalis palmaris communis from the A. ulnaris. Ateles paniscus ( $\mathrm{Schwalbe}$ ) are said to have three and Alteles arachinoides ( $\mathrm{Sch}$ w a l be) four $\mathrm{A}$. digitalis palmaris communis from the arcus palmaris superficialis having the $A$. ulnaris as the main trunk and the $A$. volaris digiti quinti ulnaris arises from the $A$. volaris digiti quinti radialis. Four A. digitalis palmaris communis arise from the A. ulnaris in Lagothrix (M a n ners-Smith), Cebus (Manners-Smith, Schw a $l \mathrm{~b}$ e) and Cebus capucinus ( $\mathrm{S} \mathrm{h}$ w a $1 \mathrm{be}$ ). However, in Chrysothrix (M a n ners-S mith), a large branch to the ulnar side of the thumb and three A. digitalis palmaris communis arise from the arcus palmaris superficialis in which the A. radialis is the main trunk. This is similar to my findings on Macacus cyclopsis. In other words, in Ceboidae such as Hapalidae, Cebidae, etc., four A. digitalis palmaris communis generally arise from the A. ulnaris.

Next, in Macacus ( $\mathrm{N}$ is hi, M a n ner s-S m ith), from the arcus palmaris superficialis in which the ramus palmaris superficialis a. radialis forms the main trunk, four A. digitalis palmaris communis are given off. $\mathrm{Zuckerkandl}$ (1908) reported that in Macacus rhesus there are four $A$. digitalis palmaris communis and the $A$. volaris pollicis radialis and the $A$. volaris digiti quinti ulnaris are small. The latter is given off by the A. ulnaris, while the A. digitalis palmaris communis II is much retrogressed and is supplemented by the A. digitalis palmaris communis $I$. This is felt to correspond to my type IV.

Four A. digitalis palmaris communis arise from the arcus palmaris superficialis in Cercocebus fuliginosus and Cynochephalus maimon ( $\mathrm{M}$ a $\mathrm{n} \mathrm{ners-S} \mathrm{m} \mathrm{i} \mathrm{t} \mathrm{h)} \mathrm{but} \mathrm{in} \mathrm{the} \mathrm{latter,} \mathrm{the} \mathrm{one} \mathrm{runing} \mathrm{to} \mathrm{the} \mathrm{opposing}$ surfaces of the thumb and index finger is large and the other three are small. Also, in Cercopithecus callitrichus (M a n ners$\mathrm{S} \mathrm{m}$ i $\mathrm{th}$ ) the arteries to the opposing surfaces of the index and middle 
fingers are absent. In Cynopithecus ( $\mathrm{M}$ a $\mathrm{n} n$ e $\mathrm{r} \mathrm{s}-\mathrm{S} \mathrm{m}$ i $\mathrm{th}$ ), there are three from the $A$. radialis and one A. digitalis palmaris communis from the A. ulnaris. In Semmopithecus ( $\mathrm{N}$ is h i), the A. digitalis palmaris communis II and III arise from the arcus palmaris superficialis, but they are small and the A. digitalis palmaris communis IV comes off of the A. ulnaris, but, in general, the arcus palmaris superficialis and the Aa. digitales palmaris communes are poorly developed. Consequently, from these findings and my own observations, it may be said that in Cercopithecidae there generally are four A. digitalis palmaris arising from the $A$. radialis or the arcus palmaris superficialis which has the $A$. radialis as the main trunk while the A. volaris digiti quinti uinaris is given off by the A. ulnaris.

In Hylobates ( $\mathrm{N}$ i s hi), the A. digitalis palmaris communis II-IV to arise from the arcus palmaris superficialis. $\mathrm{Z} \mathrm{u} \mathrm{c} \mathrm{k} \mathrm{e} \mathrm{r} \mathrm{k} \mathrm{a} \mathrm{nd} \mathrm{l}(1908)$ has noted the A. digitalis palmaris communis II-V to arise from the arch in Hylobates lar. In addition, it is reported that the A. metacarpea palmaris I was well developed and demonstrated a distribution similar to the A. princeps pollicis of man. In Troglodytes niger ( $\mathrm{Z} \mathrm{u} \mathrm{c} \mathrm{kerkand}$ ), the A. digitalis palmaris communis II-IV and the $A$. volaris digiti quinti ulnaris arise from the arcus palmaris superficialis while the A. digitalis palmaris communis $I$ has its origin in the deep region. In Hylobates ( $\mathrm{M}$ a $\mathrm{n} n$ e r s-S m it h) and Pan chimpnse (Glidde n, Garis, M a n ners-Smith), the A. digitalis palmaris communis II-IV arise from the A. ulnaris while the A. digitalis palmaris communis I comes from the arcus palmaris profundus. Gorilla gorilla (M a n ners-Sm ith, Z u ckerkand l) have no arcus palmaris superficialis, and the $\mathrm{A}$. digitalis palmaris communis I-III comes from the arcus palmaris profundus while the $A$. digitalis palmaris communis $I$ and the $A$. volaris digiti quinti ulnaris arise from the A. ulnaris. In Simia satyurus (M a n ners-S mith, $\mathrm{Zuckerkandl)}$, the A. volaris pollicls radialis, the A. digitalis palmaris communis I-IV and the A. volaris digiti quinti ulnaris arise from the arcus palmaris superficialis, but the $A$. volaris pollicis radialis is derived from the $A$. radialis and the $A$. volaris digiti quinti ulnaris is associated with the A. ulnaris.

In man A. digitalis palmaris communis I consists of three independent arteries in general. Furthermore, in most instances, each of these arterise arise from the Aa. metacarpeae palmaris (arcus palmaris profundus). However, with regared to the A. volaris pollicis ulnaris in Japanese adult, some workers claim that it mostly 
arises from the Aa. metacarpeae dorsale (42 cases, $42.0 \% \pm 4.94 \%$ ) (A d a c h i) while others say that it is more usual for it to originate from the Aa. metacarpeae palmaris (152 cases, $76.0 \% \pm 3.02 \%)$ (Y a m a moto).

The origin of the A. digitalis palmaris communis II-IV and the A. volaris digiti quinti is from the superficial arteries of the ulnar artery in the majority of cases ( $\mathrm{d} \mathrm{a} \mathrm{c} \mathrm{hi,} \mathrm{M} \mathrm{o} \mathrm{r} \mathrm{i,} \mathrm{F} \mathrm{u} \mathrm{k} \mathrm{u} \mathrm{y} \mathrm{a} \mathrm{m} \mathrm{a).}$ Furthermore, the frequency of the origin of the Aa. digitales palmares communes from the ulnar artery tends to increase from radial side to ulnar side (Adachi, Mori, Fukuyama). This tendency may be observed in Macacus cyclopsis also, but there is a difference in that those on the radial side in Macacus cyclopsis arise from the ramus palmaris superficialis a. radialis far more frequently than in man.

When the Aa. metacarpeae palmaris are considered to be deep arteries and the other arteries of the palm are regarded as superficial arteries, the origin from the deep arteries is very frequent on the radial half while in contrast to this, the origin is mainly from the superficial arteries on the ulnar half in man. The Aa. digitales palmaris arise from the deep arteries (Aa. metacarpeae palmaris and dorsales) more frequently among Asians than among Europeans. This is particularly so on the radial side of the palm. Thus a marked difference by race is said to exist.

Review of the above raveals that in Cercopithecidae and lower animals, the origin is from the superficial arteries while in higher Simiidae there is a tendency for the origin to be from the deep arteries, particular on the radial half, and the findings gradully approach that of man.

4. Ramus palmaris profundus a. ulnaris

This artery is considered to be a continuation of the A. ulnaris but is much smaller than the A. ulnaris which forms the arcus palmaris superficialis and a small branch from the A. marginalis volaris ulnaris was seen uniting with the A metacarpeae palmaris $V$ in 44 cases $(44.0 \% \pm 4.96 \%)$. The ramus palmaris profundus in man is said to be separated into the ramus palmaris profundus superior

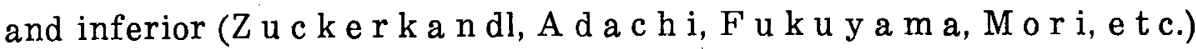
but in Macacus cyclopsis, there was no evidence of the ramus palmaris inferior. In man the frequency of the ramus palmaris profundus inferior is slightly higher in Europeans than in Asians and seems to be less frequent in fetus as compared with adult. According to 
Z u c k e r k a nd l (1896-1908), the A. ulnaris goes deep into the palm together with the ramus profundus $n$. ulnaris in Carnivoran and Rodentier. Consequently the ramus palmaris profundus is the continuation of the A. ulnaris. It either given off a very small artery to the superficial layer of the palm or the ramus palmaris superficialis is absent. However, in Prosimia and Primaten, the ramus palmaris superficialis is large while the ramus palmaris profundus is very small. Furthermore, a branch corresponding to the ramus palmaris profundus infierior of man is not present. Consequently, the ramus palmaris profundus infersior is peculiar to man and the ramus palmaris profundus superior may be regarded as a remnant of the animal type. From this fact, it is said that the ramus palmaris profundus suderior is old, while the ramus palmaris profundus inferior is new.

5. Arcus palmaris profundus and Aa. metacarpeae palmaris

As in other macacus ( $\mathrm{Nish} \mathrm{i}$ ), the arcus palmaris profundus of Macacus cyclopsis is formed by the ramus palmaris profundus a. ulnaris and anastomoses with the ramus perforans proximlis II at the radial side. From the convexity of the arch at points corresponding to the respective metacarpea bones are given off the A. metacarpea palmaris II-V which run distally and anastomose with the Aa. digitales palmaris communes. (A. metacarpea palmaris I was discussed in the section on A. metacarpea dorsalis I.)

In Macacus cyclopsis, one or two small branches from the A. interossea palmaris were seen joining the arcus palmaris profundus in 14 cases $(14.0 \% \pm 3.46 \%$ ). Also, in 42 cases (male 20, female 22) $(42.0 \% \pm 4.93 \%)$ it was observed that during the descent of the ramus palmaris superficialis a. radialis in the thenar region, a small branch is given off which penetrates the M. abductor pollicis brevis, the M. flexor pollicis brevis and the M. adductor pollicis to sink deep into the palm where it joint with the A. metacarpea palmaris I. In addition, a special case (body No. 37, female, right) was noted in which the ramus perforans distalis of the A. metacarpea dorsalis II which appears deep in the palm descends and anastomoses with the $A$. radialis indicis, while the A. metacarpea dorsalis III enters into the $\mathrm{Mm}$. interossei and anastomoses with the A. digitalis palmaris communis III. In this case, the A. metacarpea volaris III which arises from the arcus palmaris profundus is absent.

Next, the location of the arcus palmaris profundus, whether it is on the dorsal or palmar side of the ramus profundus n. ulnaris, 
was classified into the following 3 type according to the classification of A d a chi (1928).

Type I :

The arcus palmaris profundus is on the dorsal side of the ramus profundus n. ulnaris. 66 cases $(66.0 \% \pm 4.73 \%)$ were of this type. Type II :

The arcus palmaris profundus is on the palmar side of the ramus profundus $n$. ulnaris and 32 cases $(32.0 \% \pm 4.66 \%)$ were of this type.

Type III :

The arcus palmaris profundus forms an uniform or almost uniform arterial ring and penetrates the ramus profundus n. ulnaris. 2 cases $(2.0 \% \pm 1.0 \%)$ were of this type.

Next, the size of the arcus palmaris superficialis and the arcus palmaris profundus was compared and it was found that former is larger in all cases.

The arcus palmaris profundus of Lemuroidae ( $\mathrm{M}$ a $\mathrm{n} n$ e r s-S $\mathrm{m}$ it $\mathrm{h}$ ) is extremely small and in Lemur catta ( $\mathrm{Sc} \mathrm{hwalbe}$ ), the A. radialis, which penetrates the second intermetacarpal space from the back of hand to the palm, forms an arch with the ramus palmaris profundus a. ulnaris. The arcus palmaris profundus of Ateles paniscus and Ateles arachinodies ( $\mathrm{Z} \mathrm{u} \mathrm{cke} \mathrm{rkandl,} \mathrm{M} \mathrm{a} \mathrm{n} \mathrm{ners-Smith)} \mathrm{also} \mathrm{is}$ small as in Lemuroidae. In Cebus capucinus ( $\mathrm{Z} \mathrm{u} \mathrm{c} \mathrm{ke} \mathrm{rkand}$ ), the ramus perforans of the Aa. metacarpeae dorsales and the ramus palmaris profundus a. ulnaris form a small arch from which arise A. metacarpeae palmaris to between the various fingers. Also, in Chrysothrix (M n ners-Smith), the A. radialis appears in the palm from the back of hand and, after giving off the A. volaris pollicis propria and the $A$. radialis indicis, forms an arch with the ramus palmaris profundus a. ulnaris from which three Aa. metacarpeae palmaris arise. In other words, the arch is also small in Cebidae.

M a n n e s-S mith (1931) investigated Cercopithecidae such as Macacus radiatus, Macacus rhesus, Cercocebus fuliginosus, Cercopithecus callitrichus, Cynocepahlus, Cynopithecus, etc.. It is reported that the ramus palmaris profundus a. ulnaris was small and forms an arch but there is no anastomosis with the $A$. radialis. In the study of Macacus rhesus by $\mathrm{Z} \mathrm{u} \mathrm{ckerkandl}$ (1908), the A. radialis which penetrates the first intermetacarpal space from the back of hand to the palm is not related with the arch, while the A. radialis which appear on the palm from the second intermetacarpal space forms an 
arch with the ramus palmaris profundus a. ulnaris from which the A. metacarpea palmaris $\mathrm{II}-\mathrm{V}$ arise. This finding is the same as my own observations on Macacus cyclopsis.

The arcus palmaris profundus is also poorly developed in Semnopithecus, Cebus and Lagotrix ( $\mathrm{N}$ is hi). In Hylobates lar. and Trogrodytes niger ( $\mathrm{Z} \mathrm{u} \mathrm{c} \mathrm{k} \mathrm{e} \mathrm{r} \mathrm{k} \mathrm{a} \mathrm{d} \mathrm{l}$ ), the A. radialis which appears in the palm from the first intermetacarpal space forms an arch with the ramus palmaris profundus a. ulnaris from which four A. metacarpea palmaris arise and anastomose with the Aa. digitales palmaris communes. Furthermore, in Hylobates lar, the A. metacarpea palmaris I is well developed and its distribution is said to be similar to that of the A. princeps pollicis of man. The arcus palmaris profundus is not found in Simia Inunus ( $\mathrm{T}$ h e i 1). In Pan chimpanse (M a n n e r s$\mathrm{S} \mathrm{m} \mathrm{ith,} \mathrm{G} \mathrm{I} \mathrm{it} \mathrm{h,} \mathrm{G} \mathrm{a} \mathrm{r}$ is), the A. radialis appears in the palm from the first intermetacarpal space and, after giving rise to the A. volaris pollicis propria and the A. metacarpea palmaris I and II, it forms an arch with the ramus palmaris profundus a. ulnaris. From this arch is given off the A. metacarpea palmaris III. Also, there are small ramus perforans of the second, third and fourth intermetacarpal spaces which" connect the arcus palmaris profundus and Aa. metacarpeae dorsales. In Gorilla gorilla ( $\mathrm{Z}$ u ckerkand l, Manners$\mathrm{S} \mathrm{m}$ it $\mathrm{h}$ ), the $\mathrm{A}$. radialis which appears in the palm from the first intermetacarpal space forms quite a large arch with the ramus palmaris profundus a. ulnaris. From this arch arise the A. metacarpea palmaris I-III while the A. metacarpea the A. metacarpea palmaris IV originates from the superificial artery reports $\mathrm{Z} \mathrm{u} \mathrm{c} \mathrm{ke} \mathrm{rkand}$ (1908). M a n ners-Smith says that the A. metacarpea palmaris I-IV arise from the arcus palmaris profundus. In Hylobate (M a n e r s-Smith), the A. radialis which appears in thh palm from the second intermetacarpal space, forms a small arch with the ramus palmaris profundus a. ulnaris from which the A. volaris pollicis propria arises. In Simia satyrus (M a n ers-Smith, Zucker$\mathrm{k}$ a $\mathrm{nd} \mathrm{l}$ ), an arch similar to that of Hyloboates is formed, from which four small A. metacarpea palmaris arise and the A. metacarpea palmaris IV anastomoses with the A. volaris digiti quinti ulnaris but except for this there in no anastomosis between the Aa. metacarpeae of the dorsal or palmar side and the Aa. digitales palmaris communes.

In other words, in the above Simiidae, there generally is communication with the Aa. digitales palmaris communes and the 
distribution is similar to the A. princeps pollicis in man.

$\mathrm{Nishi}$ (1939) has reported that in macacus, the various $\mathrm{A}$. metacarpea palmaris anastomose with the catella volaris distails at the distal side and that a small branch from that catella anastomoses with the Aa. digitales palmares communes. Unfortunately, I was unable to confirm this finding.

From the above findings, it is presumed that the development of the arcus palmaris profundus improves from lower Prosimiae to higher Anthropoiden.

In man, the arcus palmaris profundus is formed by the anastomosis of a large terminal branch of the $A$. radialis (ramus palmaris profundus) and a small ramus palmaris profundus of the A. ulnaris. Its location is said to be dorsal to the nerve more frequently in Asian than in Europeans (A d a c h i, F u k u y ma, M o ri, Z u c k e r$\mathrm{kandl).} \mathrm{Also,} \mathrm{the} \mathrm{number} \mathrm{of} \mathrm{cases} \mathrm{in} \mathrm{which} \mathrm{the} \mathrm{arcus} \mathrm{palmaris}$ superficialis is larger than the arcus palmaris profundus and the number of cases in which the arcus palmaris superficialis is smaller than the arcus palmaris profundus are about equal (Adachi, Tadokoro). These may be said to the major differences from Macacus cyclopsis.

The essential difference in the arcus palmaris profundus between mammals and man is said to be determined by the state of the ramus palmaris profundus a. ulnaris ( $\mathrm{Zu} \mathrm{cke} \mathrm{r} \mathrm{kand} \mathrm{l}$ ).

6. Aa. digitales palmaris propriae

The main arteries distributed through the various fingers of Macacus cyclopsis are sent out from the four A. digitalis palmaris communis which arise from the arcus palmaris superficialis. I have studied the origin, course and size of these Aa. digitalis propriae.

l) Origin and course

a) Thumb

i) On the ulnar side of the thumb, an artery usually originating from the A. digitalis palmaris communis I $(98.0 \% \pm 1.40 \%)$ runs distally on the ulnar side. However, in rare cases, there is origin from the ramus palmaris superficialis a. radialis $(1.0 \% \pm 0.99 \%)$ or the $A$. metacarpea palmaris I $(1.0 \% \pm 0.99 \%)$.

ii) But on the opposite radial side, either a branch from the artery on the ulnar side is received from across the palmar side of the phalanx which separates into two branches that run up down, respectively, along the edge of the finger (90.0\%) or, instead of this branch, there is a separate artery proper to the radial side (10.0\%). 
Of the cases having this proper artery of the radial side, the origin is from A. digitalis palmaris communis I $(6.0 \% \pm 2.37 \%)$, the ramus palmaris superficialis a. radialis $(3.0 \% \pm 1.70 \%)$ or the A. metacarpea dorsalis I $(1.0 \% \pm 0.99 \%)$ with anastomosing branches to the artery on the ulnar side.

b) Index finger

i) On the ulnar side of the index finger, an artery usually arising from the A. digitalis palmaris communis II runs along the ulnar side $(90.0 \% \pm 3.00 \%)$, but in some cases the origin was from A. digitalis palmaris communis I $(8.0 \% \pm 2.71 \%)$, the A. digitalis palmaris communis III $(1.0 \% \pm 0.99 \%)$ or the A. metacarpea palmaris II $(1.0 \% \pm 0.99 \%)$.

ii) On the opposite raidal side, a branch from the ulnar side crosses to the radial side which separates into two branches that run up and down, respectively, $(44.0 \%)$ or a separate artery proper to the radial side is present $(56.0 \%)$. The origin of the latter is from the A. digitalis palmaris communis I $(43.0 \pm 4.95 \%)$, the A. digitalis palmaris communis II $(1.0 \% \pm 0.99 \%)$, the ramus palmaris superficialis a. radialis $(1.0 \% \pm 0.99 \%)$, the $A$. metacarpea dorsalis $\mathrm{I}(8.0 \% \pm 2.71 \%)$ or from the A. metacarpea palmaris I $(3.0 \% \pm 1.70 \%)$.

c) Middle finger

i) On the ulnar side of the middle finder, an artery arising from the A. digitalis palmaris communis II runs to the tip of the finger $(99.0 \% \pm 0.99 \%)$. In rare cases, the origin is from the $\mathrm{A}$. metacarpea dorsalis III $(1.0 \% \pm 0.99 \%)$.

ii) On the radial side, a branch from the ulnar side crosses to the radial side which divides into two branches that run up and down, respectively, in the radial side of the finger $(33.0 \%)$ or a separate artery proper to the radial side is present $(67.0 \%)$. Of the cases with a proper artery of the radial side, than most usual origin is from the $\mathrm{A}$. digitalis palmaris communis II $(61.0 \% \pm 4.87 \%)$. In other cases, the origination was from. the A. digitalis palmaris I $3.0 \% \pm 1.70 \%)$, the A. metacarpea dorsalis II $(2.0 \% \pm 1.40 \%)$ or A. metacarpea palmaris II $(1.0 \% \pm 0.99 \%)$.

d) Ring finger

i) An artery proper to the ulnar side is seen in $71.0 \%$. The origin in from the A. digitalis palmaris communis IV $(67 \cdot 0 \% \pm 4.70 \%)$, or the A. metacarpea dorsalis IV $(4.0 \% 1.95 \%)$. In other cases $(29.0 \%)$. a branch from the opposite side was received which divides into two branches that run up and down, respectively. 
ii) The artery on the radial side arises from the $\mathrm{A}$. digitalis palmaris communis III $(100.0 \% \pm 0.0 \%)$.

e) Small finger

i) The artery on the ulnar side is either from the A. volaris digiti quinti ulnaris $(49.0 \%)$ or a branch from the radial side (51.0\%). The origin of the former has already been discussed and will not be repeated (section on Aa. digitales palmaris communes).

ii) The artery on the radial side arises from the A. digitalis palmaris cimmunis IV in all cases.

When one side of the finger is supplied by a branch from the other side and there is no proper artery from the proximal region, and if such a state may be termed the absence of the proper artery, the frequency of absence of the respective proper arteries are as follows (Table 5).

Table 5. Absence of Aa. digitales palmares propriae.

\begin{tabular}{|l|l|l|}
\hline & Radial side & Ulnar side \\
\hline Thumb & $90(90.0 \pm 3.00)$ & 0 \\
\hline Index finger & $44(44.0 \pm 4.96)$ & 0 \\
\hline Middle finger & $33(33.0 \pm 4.70)$ & 0 \\
\hline Ring finger & 0 & $29(29.0 \pm 4.53)$ \\
\hline Small finger & 0 & $51(51.0 \pm 4.99)$ \\
\hline
\end{tabular}

The frequency of absence is high on the radial side in the thumb, index finger and middle finger and on the ulnar side in the ring and small fingers. Futhermore, in the former three fingers there is a tendency for the frequency of absence to be higher in fingers towards the radial side, and while in the latter two fingers the frequency tends to be higher towards the ulnar side.

2) Comparison of size on each side of findger

Excluding cases in which one side was supplied by a branch from the opposite side, the size of the arteries on each side was compared. In the thumb, index finger and middle finger, it was found that the artery on the ulnar side was larger in all instances except in only two cases in which the artery of the radial side of the middle finger was larger than that on the ulnar side. In the ring and small fingers, of the 71 ring fingers and 49 small fingers with artery of the ulnar side, the artery of the radial side of the ring finger was smaller than the ulnar side in one case, both arteries 
were of equal size in four cases, while in the remaining cases the artery of the radial side was larger.

In other words, the artery of the ulnar side is larger in the thumb, index finger and middle finger while the artery of the radial side is larger in the ring and small fingers. The above findings indicate that the the finger of Macacus cyclopsis has a single main artery which runs on the ulnar side in the thumb, index finger and middle finger, and on the radial side in the ring and small fingers. Furthermore, from this main artery a branch crosses to the opposite side which divides into two branches that run up and down, respectively, along the edge of the finger. These finding are consistent with the report of $\mathrm{N}$ is hi (1939), but a branch does not always run to the opposite side and in these cases there is a artery proper to that side. Even when there is a proper artery on the other side, one or two small anastomosing branches are sent out from the main artery to the opposite side.

In man, too, the Aa. digitales palmaris propriae is said to be very often larger on the ulnar side in the thumb, index finger and middle finger and larger on the radial side in the ring and small fingers ( $\mathrm{Ki}$ a $\mathrm{ra}$ ). There are large anastomosis between the $\mathrm{A}$. digitalis palmaris propria of each finger at points corresponding to the resective phalanges except the ungual phalanx which are similar to the branches crossing to the opposite side in monkey. The tip of the finger is supplied mainly by a branch from Aa. digitales palmaris propriae on the ulnar side in the three fingers on the radial side and from that on the radial side in the two fingers on the ulnar side (Y a m a moto).

\section{Summary}

I have inspected the courses of the arteries in 100 hands of Macacus cyclopsis (male 59, female 41) and obtained the following results.

1) With regard to the distribution of the A. radialis on the back of hand, it divides very frequently into two branches; one, the radial branch, goes to the first intermetacarpal space while the other, the ulnar branch, goes to the second intermetacarpal space. Furthermore, the main trunk of the artery almost always reaches the second intermetacarpal space.

2) The ramus carpeus dorsalis a. radialis divides from the main 
trunk of the A. radialis and goes to the second intermetacarpal space by a different course from that of the rete carpi dorsale or the main trunk.

3) The A. metacarpea dorsalis $I$ is a continuation of the A. radialis. It separates into two branches; one of which becomes the A. dorsalis pollicis ulnaris and the other becomes the A. dorsalis indicis radialis.

The A. metacarpea dorsalis II is a continuation of the ulnar branch of the A. radialis but the A. metacarpea dorsalis III and IV arises from the rete carpi dorsale, the ramus carpeus dorsales or the arcus volaris profundus. However, there is a greater tendency of palmar origin in the A. metacarpea dorsalis IV than in the A. metacarpea dorsalis III.

4) The rete carpi dorsale is formed by the ramus carpeus dorsalis of the A. radialis and ulnaris, the A. interossea posterior and the ramus dorsalis of the A. interossea anterior. It divides into a deep and superficial layer.

5) The so-called catella dorsalis proximalis which connect the various A. metacarpea dorsalis is found in all cases, but a considerable number of cases demonstrate an incomplete arch formation.

6) The ramus palmaris superficialis a. radialis separates from the $A$. radialis at the middle of the forearm and descends side by side with the A. radialis to the Proc. styloideus of the radius where it changes its direction and penetrates the M. adbuctor pollicis brevis to the palm.

Comparison of the size of the ramus palmaris superficialis a. radialis with the $A$. radialis and the $A$. ulnaris revealed the ramus palmaris superficialis :a. radialis to be the largest artery in the palm.

7) The arcus palmaris superficialis is formed by the A. ulnaris and the ramus palmaris superficialis a. radialis. In the majority of cases, the latter is dominant.

8) The Aa. digitales palmares consists of the A. digitalis palmaris communis I-IV and the A. marginalis volaris ulnaris, the origin is from the superficial arteries of the palm.

9) The ramus palmaris profundus a. ulnaris is extremely small and no vessel corresponding to the ramus palmaris profundus inferior of man is found.

The ramus palmaris profundus a. ulnaris froms the arcus palmaris profundus but this arch is most frequently located dorsally 
to the ramus profundus $n$. ulnaris.

10) The A. digitalis palmaris propria of the various fingers are well developed on the ulnar side of the thumb, index finger and middle finger, and on the radial side of the ring and small fingers. They form the main artery of each fingers. Usually, a branch crosses to the opposite side from these main arteries which divide into two branches that run up and down, respectively, on the opposite edge of the finger.

\section{Literature Cited}

1) Adachi, B.: Über die anthroporogische Angiologie der Japaner. (Japanisch) Tokyo Igk. Z., Bd. 10, 1889.

2) A d a ch i, B.: Arteriensystem der Japaner. Bd. 1, Kyoto, 1928.

3) Bang, F. B.: Observations on Limb Arteries of the Woolly Monkey. Ant, Rec., vol. 66, 1936.

4) F u k u y ma, U.: On the arteries of the upper extremity in northern Chinese (Japanese). J, Orient Med., Vol, 29, 1928,

5) Göppert, E.: Die Beurteilung der Arterienvarietäten der oberen gliedmassen bei den Säugetiere und beim Menschen auf Entwicklungsgeschichtlicher und Vergleichend-Anatomischer Grundlage. Ergeb. Anat. Entwick. Bd. 14, 1904.

6) Glidde n, E. M. and C. F. Garis: Arteries of the Chimpanzee. Amer. J. Anat. Vol. 58, 1936.

7) Kihara, Y.: Forms of the Arteries of the Hand of Japanese (Japanese). Seiikai Z., Vol. 61, 1942.

8) Loth, E.: Anthropologie de parties molles. Paris, 1931.

9) Li ne back, P.: Chapter XII. "The Vascular System" in the Anatomy of the Rhesus Monkey. Edited by Carl G. Hartman. Baltimore, 1933.

10) M ü 11 e r, E.: Beiträge zur Morphologie des Gefässsystems. Anat. Heft. 27, 1904

11) Manne.rs-Smith,T.: The limb arteries of Primates. J. Anat. \& Phys., Vol. 45, 1911.

12) Mori, Y.: On the Arteries of the neck and upper extremity in Japanese fetuses (Japanese): Kaibo Z., Vol. 16, 1940.

13) Mori, Y.: On the Arteries of the upper extremity in Japanese fetuses (Japanese). Kaibo Z., Vol. 17, 1941.

14) Nishi, S.: Über die Arterien der Affenhand. Ein Beitrag zur vergleichenden Angiologie. Japan J. med. Scien. II ANATOMY, Vol. VII, 1939.

15) $\mathrm{N}$ is h i, S.: On the Arteries of the Hand (Japanese), Kaibo Z., Vol. 14, 1939.

16) Schwalbe, E.: Zur vergleichenden der Unterarmarterien, speziell der Arcus volaris sublimis. Morph. Jahrb, Bd. 33, 1895.

17) Sonntag, C. F.: On the anatomy, physiology and pathology of the Chimpanzee. Proc. Zool. Soc. 1, 1928.

18) Sonntag, C. F.: The morphology and evolution of the apes and man. London, 1924.

19) The il e, W. F.: Über das Arterlensystem von Simia inunus. Müller Arch. 1852.

20) Tadok or o, Y.: Measurement of the Arteries of Japanese (Japanese). Kaibo Z., Vol. 2, 1929. 
21) Y a ma moto, H.: Anatomisch-steroskopische Röntgenuntersuchungen über die Hand- und Fingerarterien der Japaner (Japanisch). Kaibo Z., Bd. 13, 1939.

22) Zuckerkandl, E.: Über die tiefen Hohlhandäste der A. ulnaris. Anat. Heft. 6, 1896.

23) Zu ckerkand 1, E.: Zur Anatomie und Morphologie der Extremitätenarterien. Wiener. Sitzungsberichte, Mathem. Naturw. Klasse, Bd. 116, 1908. 